\title{
O NÃO LUGAR DA FORMAÇÃO AMBIENTAL NA EDUCAÇÃO BÁSICA: REFLEXÕES À LUZ DA BNCC E DA BNC-FORMAÇÃO
}

\author{
ALINE LIMA DE OLIVEIRA NEPOMUCENO ${ }^{1}$ \\ Orcid: https://orcid.org/0000-0001-7936-2167 \\ MÔNICA ANDRADE MODESTO ${ }^{2}$ \\ Orcid: https://orcid.org/0000-0002-9457-2725 \\ MARIANA REIS FONSECA ${ }^{3}$ \\ Orcid: https://orcid.org/0000-0003-3620-1317 \\ HEVELY CATHARINE DOS ANJOS SANTOS ${ }^{4}$ \\ Orcid: https://orcid.org/0000-0003-2071-3393
}

\begin{abstract}
RESUMO: Os lugares ocupados pelas discussões no currículo dizem muito sobre a intencionalidade e sobre os interesses que circundam os documentos norteadores da educação brasileira. À vista disso, e com base no aporte teórico relacionado ao pensamento complexo e à Educação Ambiental crítica, o presente estudo versa sobre a identificação do lugar ocupado pela formação ambiental na Base Nacional Comum Curricular (BNCC) e na Base Nacional Comum para a formação inicial e continuada de professores da Educação Básica (BNC-Formação). Analisa-se, por meio de estudo documental e à luz da Análise Textual Discursiva, que o que de fato se delineia nos documentos mencionados é um não-lugar para a formação ambiental, convergindo, assim, para o silenciamento dos preceitos da Educação Ambiental crítica na Educação Básica e no Ensino Superior, este último no que diz respeito a cursos de licenciatura. Nesse sentido, os resultados desvelaram que a discussão socioambiental é objeto de generalização na BNCC e de invisibilização na BNC-Formação, demonstrando, desse modo, como tais documentos configuram-se como instrumentalizadores de uma formação reprodutora dos interesses da ordem dominante e do status quo e arraigada ao paradigma simplista e fragmentador da produção do conhecimento, o que impossibilita a percepção crítica e complexa da realidade.
\end{abstract}

Palavras-chave: Base Nacional Comum Curricular, Formação docente, Educação Ambiental.

\section{THE NON-PLACE OF ENVIRONMENTAL TRAINING IN BASIC EDUCATION: REFLECTIONS IN THE LIGHT OF BNCC AND BNC-TRAINING}

\footnotetext{
${ }^{1}$ Universidade Federal de Sergipe (UFS). São Cristóvão, SE, Brasil. <alinenepo@academico.ufs.br>

2 Universidade Federal de Sergipe (UFS). São Cristóvão, SE, Brasil. < monicamodesto1@gmail.com>

${ }^{3}$ Universidade Federal de Sergipe (UFS). São Cristóvão, SE, Brasil. < mari.r.fonseca@hotmail.com>

${ }^{4}$ Universidade Federal de Sergipe (UFS). São Cristóvão, SE, Brasil. < velyn_cas@hotmail.com> Educação em Revista|Belo Horizonte|v.37|e26552|2021
} 


\begin{abstract}
The places occupied by discussions in curriculum say a lot about the intentionality and about the interests that surround the guiding documents of Brazilian education. Considering this and based on the theoretical contribution related to complex thinking and to critical Environmental Education, this study discusses the identification of the place occupied by environmental education in the Base Nacional Comum Curricular (BNCC) and in the Base Nacional Comum for the initial and continued training of Basic Education teachers (BNCFormação). It analyses, through a documentary study and in the light of the Discursive Textual AnalysisAnálise, that what in fact delineate itself in the documents is a non-place for environmental training, thus converging to the silencing of the precepts of critical Environmental Education in Basic Education and Higher Education, this last one regarding to licentiate courses. In this sense, the results revealed that the socio-environmental discussion is presented in a generic way in the BNCC and in an invisible way in the BNC-Formation, demonstrating how such documents configure themselves as instrumentalizers of a reproductive formation of the interests of the dominant order and the status quo and rooted to the simplistic and divider paradigm of knowledge production, which makes impossible the critical and complex perception of reality.
\end{abstract}

Keywords: Common National Curriculum, Teachers training, Environmental Education.

\title{
EL LUGAR NO DE LA FORMACIÓN AMBIENTAL EN LA EDUCACIÓN BÁSICA: REFLEXIONES A LA LUZ DEL BNCC Y LA FORMACIÓN BNC
}

RESÚMEN: Los lugares ocupados por las discusiones en el currículo dicen mucho sobre la intencionalidad y los intereses que rodean los documentos rectores de la educación brasileña. En vista de esto y sobre la base de la contribución teórica relacionada con el Pensamiento Complejo y la Educación Ambiental Crítica, este estudio se ocupa de la identificación del lugar ocupado por la formación ambiental en la Base Común de Currículos Nacionales (BNCC) y la Base Nacional Común para la formación inicial y continua de los maestros de Educación Básica (BNC-Formação), verificando, a través de estudios documentales y a la luz del Análisis Textual Discursivo, que se delinea en los documentos mencionados es un no-lugar para la formación ambiental, convergiendo así al silenciamiento de los preceptos de la Educación Ambiental crítica en la Educación Básica y la Educación Superior con respecto a los cursos de formación docente. En este sentido, los resultados revelaron que la discusión socioambiental es objeto de generalización en el BNCC y de invisibilidad en la Formación BNC, demostrando así cómo tales documentos se configuran como instrumentalizadores de una formación reproductiva de los intereses del orden dominante y el status quo y arraigados en el paradigma simplista y fragmentario de la producción de conocimiento, haciendo imposible la percepción crítica y compleja de la realidad.

Palabras clave: Base Común de Currículos Nacionales, Educación Ambiental, Formación docente.

\section{CONSIDERAÇÕES INICIAIS}

Com a homologação da Base Nacional Comum Curricular para a Educação Básica - BNCC (BRASIL, 2018) em 2018, o Conselho Nacional de Educação (CNE) decidiu revisar as Diretrizes Curriculares Nacionais para a formação inicial em nível superior (cursos de licenciatura, cursos de formação pedagógica para graduados e cursos de segunda licenciatura) e para a formação continuada, elaborando a Resolução CNE/CP n²/2019 (BRASIL, 2019). O intuito dessa elaboração foi contemplar os aspectos definidos para o primeiro documento, sob a justificativa de que é necessário "desenvolver um conjunto de competências profissionais que os qualifiquem para uma docência sintonizada com as demandas educacionais de uma sociedade cada vez mais complexa" (BRASIL, 2019, p. 01).

A Resolução CNE/CP n²/2019 reformula a Resolução CNE/CP n²/2015, define as Diretrizes Curriculares Nacionais para a formação inicial de professores para a Educação Básica e institui 
a Base Nacional Comum para a formação inicial de professores da Educação Básica (BNC-Formação) (BRASIL, 2015). A partir dessas políticas públicas, cabe, neste texto, analisarmos o lugar da formação socioambiental na Resolução CNE/CP n²/2019, uma vez que esta se configura como uma demanda não somente educacional, mas também basilar da sociedade complexa, conforme aponta a Agenda 2030 prevista pela Organização das Nações Unidas (ONU), com cujo cumprimento o Brasil está comprometido.

Cabe salientarmos que entendemos que o processo de formação docente não se reduz ao treinamento e à capacitação (NÓVOA, 1995; SCHÖN, 1995), tão pouco à transmissão de conhecimentos, mas é, acima de tudo, uma reconstrução de valores éticos, uma valorização da práxis refletida. Assim, Pimenta e Ghedin (2002) afirmam que a reflexão sobre as contradições no processo de formação de professores(as) ganha uma outra dimensão, centrada na investigação do próprio trabalho em sala de aula e, logo, na escola, como pretendemos com as reflexões e análises que trazemos à baila.

Desse modo, a formação dos(as) educadores(as) ambientais desvincula-se de padrões dominantes de poder, ao serem buscadas mudanças conceituais e atitudinais e a ressignificação de valores, para que os(as) professores(as) possam atuar de forma autônoma e propositiva na transformação do espaço escolar e do contexto social da comunidade em que vivem, agindo em prol da construção de novos significados para a complexidade das relações entre os seres humanos, a sociedade e a natureza. A esse debate, Tardif (2008) acrescenta que a formação para o ensino não pode limitar-se a conhecimentos e competências, devendo também envolver valores, compromissos normativos e convicções éticas, já que o(a) professor(a) trabalha "com, sobre e para seres humanos em desenvolvimento e aprendizado. Trata-se, no sentido forte, de um trabalho de interações humanas" (TARDIF, 2008, p. 41).

Com isso, pretendemos contribuir com o campo de discussão que desvela apropriações e ressignificações de importantes categorias referenciadas por uma práxis pedagógica contra-hegemônica, capaz de intervir na realidade e de contribuir com o enfrentamento da grave crise socioambiental da atualidade. A concretização dessa intenção referencia e instrumentaliza a inserção de uma perspectiva crítica de Educação Ambiental (EA) junto à sociedade brasileira. A motivação para a realização desse intento perpassa pela reflexão sobre a formação de educadores ambientais, na tentativa de compreender, sobretudo, como as políticas públicas desse campo remetem à formação desses sujeitos, entendendo-as como um projeto político que busca verdadeiramente melhorias para a Educação Básica (EB). Dessa forma, pensar a formação de educadores superadora de "armadilhas hegemônicas" do/no processo educativo é, também, pensar a formação do educador-reflexivo, do educador ambiental crítico, e participativo que, na reflexão e na transformação atitudinal, possa buscar um real desenvolvimento da sociedade no âmbito de um padrão civilizatório diverso do atual.

Diante do exposto, procuramos, como objetivo para este escrito, identificar o lugar da formação ambiental na BNCC e na BNC-Formação, adotando como procedimentos metodológicos neste estudo qualitativo as seguintes etapas: a) levantamento e estudo bibliográfico; b) análise documental com base na técnica da Análise Textual Discursiva (ATD); e c) interpretação dos resultados. Para tanto, a primeira etapa tomou como aporte teórico os estudos relacionados ao pensamento complexo e à tendência crítica da Educação e, particularmente, da EA, utilizando como fontes os documentos disponibilizados no portal eletrônico do Ministério da Educação (MEC), a saber: Base Nacional Comum Curricular e Resolução CNE/CP n²/2019.

A análise documental partiu do princípio de que todo texto, mesmo o que está presente em documentos oficiais, diz respeito a conteúdos provenientes de discursos permeados pelas intencionalidades daqueles que os estruturaram. Nessa direção, a análise perpassou pela identificação das unidades de sentido emergentes dos arranjos discursivos presentes nos textos; pela categorização dessas unidades e pela interpretação das mesmas, que, por sua vez, possibilitaram compreender e/ou ressignificar conhecimentos pré-existentes ou elaborados sobre um tema em curso de investigação (MORAES; GALIAZZI, 2013).

A interpretação dos dados decorreu da compreensão da ATD interseccionada pelos sentidos emergentes do aporte teórico selecionado, que aqui corresponde a leituras que nos convidam a refletir sobre a necessidade de pensarmos para além da identificação das emergências que sobressaem dos documentos, pois é mister que não só apontemos os caminhos da ressignificação/transformação, mas 
que sejamos também insurgentes quanto ao status quo e às estratégias que são traçadas para a sua manutenção perante a educação.

À vista disso, este escrito está dividido em duas partes. A primeira tece reflexões relacionadas à formação de educadores e às políticas públicas em questão, sob o olhar da teoria da complexidade e do "não lugar". Já na segunda parte, analisamos a dimensão formativa da EA na BNCC e o projeto político que a circunda.

\section{O LUGAR DA FORMAÇÃO SOCIOAMBIENTAL NA SOCIEDADE COMPLEXA}

O modo como o conhecimento passou a ser produzido na sociedade organizada pelo paradigma simplificador, pautado pelo reducionismo característico da Modernidade que dicotomiza e fragmenta a complexidade da integralidade do objeto em prol das subdivisões em áreas de saber (MORIN, 2015), contribui para que entendamos o(s) lugar(es) ocupados pelos elementos e objetos e suas múltiplas perspectivas e possibilidades de atingir vários lugares, ou mesmo não-lugares, frente aos campos de estudo.

De acordo com Augé (1994), a ideia de lugar, diferentemente da ideia de espaço, não diz respeito à territorialidade, mas sim ao simbolismo, posto que o lugar é antropológico e, portanto, é identitário, relacional e histórico. Nesse sentido, o lugar não é estático, é transitório, o que ocasiona, por conseguinte, a transitoriedade da identidade que se molda em conformidade com o contexto do qual faz parte. Entretanto, durante o cotidiano, transitamos por diversos não-lugares que, segundo o autor, são os espaços provisórios que nos colocam em contato com outras formas de percebermos o mundo e de nos percebermos momentaneamente, como aeroportos, terminais rodoviários, estações de transporte público, supermercados, shoppings centers, hotéis, entre outros, mobilizando percepções identitárias transitórias que se dispersam quando retornamos ao nosso lugar (AUGÉ, 1994).

Todavia, com o avanço do fenômeno da globalização econômica, ocorrido a partir dos anos 1990, passamos a vivenciar a era da "instantaneidade de transporte da informação", que, de uma maneira esfaceladora e ilusória para as classes populares, rompe com barreiras geográficas através de formas de comunicação ínferas, ocasionando modificações severas nos modos de viver e a instrumentalização de desejos de obtenção de elementos de outros espaços e culturas, desejos esses impulsionados pelo consumismo (BAUMAN, 1999).

Sob esse ponto de vista, os lugares pensados por Augé (1994), que eram entremeados pelas tradições ${ }^{5}$, passam a sentir os impactos de um fenômeno que busca uniformizar mundialmente pensamentos e sentimentos cosmopolitas e homogeneizar as negociações culturais que se desdobram dentro das múltiplas culturas em nome da manutenção e do controle do poder local, ocasionando, assim, ambiguidades de significações que geram crises de identidade e modificações de modos de viver (BAUMAN, 2003).

Nesse cenário, o consumismo global passa a ser uma linguagem comum a todos, porém acessada de forma desigual nos espaços considerados centros e nas periferias do mundo econômico, desencadeando-se, assim, uma pulverização da globalização que se refletirá nas tradições que passam por um processo brusco de tradução ${ }^{6}$ baseado em novas posições de identificação, gerando-se o que Hall (2005) denomina de identidades flutuantes.

Mediante essa conjuntura, os não-lugares emergentes da globalização econômica e dos modus vivendi e operandi das sociedades ditados pelo consumismo promovem a generalização das características das identidades dos povos, gerando uma pseudofamiliarização com os aspectos do mundo do consumo e obscurecendo a capacidade de percepção das desigualdades intrínsecas a esse mundo, que é camuflada pela falsa sensação de poder e de prestígio que os atos consumistas proporcionam aos sujeitos.

\footnotetext{
${ }^{5} \mathrm{O}$ conceito de tradição está ligado à memória e ao passado. Nesse caso, a memória executa o papel de alimentar e de retroalimentar-se de lembranças, rituais, hábitos, costumes, entre outros elementos, para evitar que caia no hibridismo e na fluidez da contemporaneidade (HALL, 2005).

${ }^{6}$ Tradução diz respeito ao transporte entre fronteiras. É o movimento de aceitação do hibridismo e das culturas híbridas, de desprendimento do passado (HALL, 2005).
} 
A absorção dos não-lugares pelas sociedades contemporâneas como lugares perante a globalização econômica tem desencadeado uma uniformização global que, à medida que avança, impede a percepção dos elementos contextuais presentes na formação identitária, que passa a ser pulverizada e invadida pelas generificações que o consumismo fomenta. Isso solapa as tradições estruturantes e constituintes das sociedades e, consequentemente, leva ao arrefecimento do sentimento de pertencimento aos lugares e de união entre os sujeitos que os habitam. Tal argumento fora pensado por Augé (1994) e vem sendo corroborado por pensadores como Stuart Hall (2005) e Bauman (2003) por meio da expressão hibridismo cultural que, na prática, materializa-se na uniformização mundial de pensamentos e sentimentos cosmopolitas a partir da homogeneização das negociações culturais, ocasionando, assim, ambiguidades de significações que geram crises identitátias e modificações nos modos de viver que, por sua vez, passam a ser ditados pelo consumismo impulsionado pela globalização.

Remeter essa ideia de lugar e de não-lugar à formação dos sujeitos na sociedade complexa torna-nos possível perceber como, aos poucos, a relação entre os sujeitos e o ambiente tem sido atravessada pelos impactos que a globalização econômica e o consumismo desencadeiam frente à percepção do mundo. Retomando o pensamento de Edgar Morin (2015), afirmamos que um dos desafios da contemporaneidade consiste na tarefa de pensar a produção de conhecimento e a formação de sujeitos no âmbito da complexidade que traz, em seu bojo, o entendimento dos sistemas físicos, biológicos e antropossociológicos sob a égide da pluralidade e da evolução humana para além do dualismo corpo/mente e da forma dialógica de desenvolvimento das relações que culminam na formação de um pensamento complexo.

\footnotetext{
No seio dessa complexidade, também para entendê-la e nela sobreviver, compreende- se que é imprescindível perceber a realidade atual sob uma ótica dialética. Os seres humanos são produtos e produtores de sua história e possuem, dentro dessa perspectiva, o poder de interferir sobre seu futuro social, longe de práticas mercantilistas e homogeneizadoras que instalam a apatia e a consciência individualizante do pouco para muitos e do muito para poucos (OLIVEIRA, 2012, p. 02).
}

À luz do pensamento complexo, o conhecimento deixa de ser estruturado na busca por verdades absolutas e passa a ser fundado em uma razão aberta, isto é, na abertura perceptiva do mundo, que é entendido como um sistema no qual a complexidade está nas relações, e não nas partes que o constituem. Desse modo, a produção do conhecimento e a formação dos sujeitos perpassam pelo reconhecimento de saberes e de vivências como elementos legítimos e inerentes ao processo; pela compreensão de que a ciência e a tecnologia não são salvadoras nem devem ter caráter salvífico; e pela indignação com a cultura do consumo, que, em prol do conforto de uns, ignora as condições daqueles que vivem em situações de guerra, miséria e vulnerabilidade extremas, desastres ambientais, entre outras circunstâncias negativas, colocando em xeque a sobrevivência do planeta e da própria espécie humana (MORIN, 2000).

Nessa direção, Guimarães (2004) aponta para o fato de que o atual modelo é antagônico e incompatível com o estabelecimento de relações em uma realidade complexa e pretensamente socioambientalmente sustentável. Isso se confirma, porque essa sociedade atual, cada vez mais complexa e planetária, foi construída sob um paradigma que fragmenta, simplifica e reduz a compreensão da realidade, um paradigma que crê na autonomia absoluta dos sujeitos, tornando-os cada vez mais individualistas. Nesse contexto, tal modelo de sociedade do capital e para o capital perpetua-se como hegemônico e caminha a passos largos rumo à degradação da qualidade de vida humana.

O pensamento complexo idealizado por Edgar Morin $(2000,2015)$ aponta para a necessidade de formação de sujeitos aptos a compreender a multidimensionalidade do sistema Terra e das inter-relações coexistentes nele. À vista disso, no Paradigma da Complexidade, a compreensão de planeta ultrapassa a ideia de "casa", deixando de ser somente o espaço que habitamos para ser unitas multiplex, um sistema que emerge da multiplicidade dos fenômenos que ocorrem no cosmos, no universo, no planeta e em nós, um lugar no qual, diante dessa multiplicidade, constituímos nossa identidade levando em consideração a nossa relação com a Terra, reconhecendo-nos nessa relação e nos entendendo como cidadãos planetários, conscientes de que cuidar do planeta é também cuidar de nós, e vice-versa. 
Sendo assim, pensar a formação dos sujeitos no Paradigma da Complexidade implica, consequentemente, pensar sobre o lugar das discussões ambientais nos currículos dos processos formativos. Isso porque, para que possamos afirmar que formas de ver o mundo diferentes das que a ciência moderna propiciou são possíveis, precisamos pensar em caminhos de formação que ultrapassem os limites postos pela disciplinarização e as fronteiras existentes nas relações entre teoria e prática, historicamente dicotomizadas.

O agravante desse tipo de concepção dicotomizada é que o paradigma dominante da sociedade moderna, em sua racionalidade, reforça a visão fragmentada, dualista e dicotômica de mundo e naturaliza a separação entre o refletir e o agir. Nesse sentido, chamamos a atenção para a importância da práxis como reflexão e ação, como teoria e prática, realizando-se concomitante e reciprocamente em direção à constituição de um novo paradigma junto à construção de uma sociedade ambientalmente sustentável, o que remete ao campo e à importância da EA.

De acordo com a Política Nacional de Educação Ambiental (PNEA) - Lei no 9.795/1999 (BRASIL, 1999) - e com as Diretrizes Curriculares Nacionais para a Educação Ambiental (DCNEA) Resolução CNE/CP n 2 2/2012 -, o enfoque holístico do ambiente é o princípio primeiro da EA. Isso consiste em compreender o ambiente em sua inteireza, ética e de modo solidário, sem que haja hierarquização entre as espécies e sem que a exploração do meio seja considerada como forma principal de obtenção de lucro.

Essa concepção holística de ambiente remete à formação ambiental. Segundo Leff (2007, p. 254), essa formação consiste em um processo "mais orgânico e reflexivo de reorganização do saber e da sociedade na construção de novas capacidades para compreender e intervir na transformação do mundo". Logo, formar ambientalmente um sujeito diz respeito à promoção de processos formativos pautados na interpretação e na ressignificação dos axiomas que fundamentam as perspectivas de ser e de estar no mundo e com o mundo, buscando-se direcionar o desenvolvimento de práxis pedagógicas que possam se desdobrar em mudanças atitudinais.

Nesse sentido, Guimarães (2004) afirma que, mesmo com a crescente difusão da EA no processo educacional, a dimensão ambiental, muitas vezes, se apresenta fragilizada nas práticas docentes em que predomina um fazer pedagógico de caráter conservador. Afirmação esta que vem sendo confirmada ao longo dos tempos por estudos de Layrargues (2012, 2019) e Trein (2012) que desvelam que, mesmo diante dos avanços teórico-epistemológicos presentes no campo da educação ambiental, o que se observa nos discursos e práticas presentes no tecido social é uma espécie de continuum conservacionista e pragmático presentes em práticas orientadas e, de certa forma, condicionadas pelos paradigmas da sociedade moderna que levam à reprodução de uma realidade estabelecida pela racionalidade hegemônica. Nesse caso, os professores estão submersos (inconscientemente) na visão (paradigmática) fragmentária, simplista e reduzida da realidade, e, ao desperceberem-na assim (e, portanto, não a problematizarem), reproduzem (inconscientemente) esses referenciais (paradigmáticos) em suas ações pedagógicas, o que resulta em práticas ingênuas e fragilizadas de EA. Essas práticas se mostram pouco eficazes para intervirem de forma significativa no processo de transformação da realidade socioambiental, configurando-se como conservadoras por não mudarem o que já está posto. Esse é o sentido da expressão "armadilha paradigmática" cunhada por Guimarães (2004), para pensar um dos enfrentamentos da formação do educador ambiental.

Para que se torne exequível, a formação ambiental funda-se em concepções epistemológicas que se coadunam com a macrotendência crítica da EA, que vislumbra a educação como instrumento potencializador da desnaturalização da problemática socioambiental, tendo como cerne a formação de cidadãos que se reconheçam como seres históricos, globais, multicondicionais e complexos, capazes de agir pela transformação do cenário de "coisificação de tudo e de todos, de banalização da vida, de individualismo exacerbado e de dicotomização do humano como ser descolado da natureza" (LOUREIRO, 2012, p. 94) que tem sido difundido pela cultura do consumo.

Assim, para que a formação ambiental seja uma realidade na EB, é preciso que a formação docente também esteja pautada nos princípios da EA crítica, constituindo-se como uma formação

\footnotetext{
7 "Produto e produtora de uma leitura de mundo e um fazer pedagógico atrelado ao 'caminho único', traçado pela racionalidade dominante da sociedade moderna e que busca ser inquestionável” (GUIMARÃES, 2004, p. 123). Educação em Revista|Belo Horizonte|v.37|e26552|2021
} 
ambiental docente comprometida com o desenvolvimento de agentes da transformação social imbuídos de criticidade, conscientes da realidade e fundamentados pelo diálogo, pela reflexão e pela ação no mundo.

Por isso, ao discutirmos a formação em EA, torna-se imprescindível destacarmos o papel da universidade, pois esta desempenha uma tarefa fundamental nos processos de transformação do conhecimento e de mudança sociais, a partir do movimento contra-hegemônico que também deve se fortalecer nos espaços acadêmicos (OLIVEIRA, 2012). Infelizmente, a maioria dos programas de formação dificilmente estimula os licenciados a levarem a sério o papel de intelectual que trabalha em benefício de uma visão emancipatória: "Do ponto de vista dos interesses dominantes, não há dúvida de que a educação deve ser uma prática imobilizadora e ocultadora de verdades" (FREIRE, 1996, p. 99).

Dessa maneira, o lugar da formação ambiental na sociedade complexa é o lugar de elemento e de instrumento basilar e constituinte da identidade de sujeitos críticos e mobilizados pelo sentimento de pertencimento às tradições que estruturam o contexto no qual vivem e do qual advêm. Logo, esses sujeitos percebem-se dispostos a enfrentar a problemática socioambiental que os acomete por meio de uma visão de mundo ressignificada em relação à cultura do consumo instaurada pela globalização econômica.

\section{O MODELO DE FORMAÇÃO AMBIENTAL NA BNCC}

De acordo com o texto base da BNCC, esta constitui-se como "um documento de caráter normativo que define o conjunto orgânico e progressivo de aprendizagens essenciais que todos os alunos devem desenvolver ao longo das etapas e modalidades da Educação Básica” (BRASIL, 2018, p. 7). Dessa forma, esse documento oficial se funda como orientação educacional para a construção dos currículos obrigatórios em todos os níveis e modalidades de ensino, associadamente a políticas públicas da EB desenvolvidas em níveis nacionais. Por conseguinte, direciona o currículo como fundamento comum para todo o país e interliga-se ao desenvolvimento e à concretização da gestão escolar, no intuito de promover saberes e conhecimentos críticos e emancipatórios que estabeleçam ligação no processo de formação socioeducacional.

Nesse contexto de processo formativo socioeducacional, o não-lugar da formação socioambiental se estabelece nitidamente na terceira reformulação da BNCC, aprovada em dezembro de 2017 pelo CNE, a qual contempla a Educação Infantil (EI) e o Ensino Fundamental (EF), a abordagem do tema Meio Ambiente (MA) e da temática Educação Ambiental (EA). Esse texto normativo, que estabelece objetivos e diretrizes para a $\mathrm{EB}$, vem se constituindo de uma maneira reducionista perante as questões socioambientais, como é possível verificar no excerto a seguir:

Assim, busca-se promover e incentivar uma convivência em maior sintonia com o meio ambiente, por meio do uso inteligente e responsável dos recursos naturais para que estes se recomponham no presente e se mantenham no futuro (BRASIL, 2017, p. 279).

Com efeito, é importante destacar padrões sustentáveis, mas precisamos problematizar questões inerentes e hegemônicas presentes em nossa sociedade, tais como nosso sistema de capital avassalador, que assola o meio ambiente e potencializa as problemáticas socioambientais. É preciso, fundamentalmente, amadurecimento crítico e social dessas discussões que são estabelecidas nas políticas públicas, no currículo, na infraestrutura e na gestão escolar. No entanto, existe a tendência de a EA se esvaziar no currículo e, consequentemente, no espaço escolar, fragmentando o saber a partir do embasamento nas relações de dominação, sem historicidade em sua abordagem.

Ainda, na BNCC, preceituam-se "competências gerais da Educação Básica” (BRASIL, 2017, p. 9), das quais destacamos a de número 7 :

Respeitem e promovam os direitos humanos, a consciência socioambiental e o consumo responsável em âmbito local, regional e global, com posicionamento ético em relação ao cuidado de si mesmo, dos outros e do planeta (BRASIL, 2017, p. 9).

Destacamos que essas questões socioambientais se resumem, no texto, à consciência ambiental e ao consumo responsável para a qualidade de vida, quando se poderia também destacar Educação em Revista|Belo Horizonte|v.37|e26552|2021 
conceitos como sustentabilidade, autonomia e emancipação, visto que são esses os aportes teóricos que alicerçam o desenvolvimento da consciência socioambiental, o consumo responsável e o cuidado com o planeta. Partindo do pressuposto da incorporação de uma educação contextualizada, interdisciplinar e significativa, observamos que a realidade dos autores e atores educacionais é importante e de extrema valia para o aprofundamento das discussões da temática $E A$, pois vemos que, ante a crise, a EA se estabelece como um considerável instrumento de investigação crítica na busca por uma educação transformadora, emancipatória e reflexiva. Como enfatiza Guimarães (2016), "os problemas ambientais, que são decorrência de um modelo de desenvolvimento econômico de forte impacto ambiental em que a Educação Ambiental é uma importante ação para a superação destes problemas" (GUIMARÃES, 2016, p. 14). Nesse contexto, a importância de se contextualizar uma EA crítica no ensino remete a um direito fundamental inerente ao ser subjetivo, parte integrante e coletiva do meio ambiente.

No que diz respeito aos cenários mais relacionados ao debate da temática EA na BNCC, a área de Ciências da Natureza é concebida como o espaço de saberes próprio para o desenvolvimento de "ações de intervenção para melhorar a qualidade de vida individual, coletiva e socioambiental" (BRASIL, 2017, p. 321). É reconhecida nesse trecho a importância de ações e de projetos em EA, porém evidenciamos que, além dessa inserção, é preciso haver relação da conjuntura trabalhada com a realidade local e que atividades socioambientais sejam contempladas de forma contínua e interdisciplinar, a fim de se conceber um processo educacional significante aos contextos socioambientais. Portanto, além de se inserirem determinados termos no documento oficial posto em análise, é preciso haver uma discussão amadurecida sobre a EA crítica que promova um olhar crítico sobre a realidade. Conforme pontua Freire (1979, p. 15),

A conscientização implica, pois, que ultrapassemos a esfera espontânea de apreensão da realidade, para chegarmos a uma esfera crítica na qual a realidade se dá como objeto cognoscível e na qual o homem assume uma posição epistemológica (FREIRE, 1979, p. 15).

Por conseguinte, e em consonância com as áreas de ensino de Geografia, no $6^{\circ}$ item da BNCC têm-se as seguintes ações:

Construir argumentos com base em informações geográficas, debater e defender ideias e pontos de vista que respeitem e promovam a consciência socioambiental e o respeito à biodiversidade e ao outro, sem preconceitos de qualquer natureza (BRASIL, 2017, p. 366).

Essa perspectiva trata da consciência socioambiental, desenvolvida de modo a não distanciar sociedade e meio ambiente, em um contexto de respeito às diversidades vistas no espaço intercultural. Contudo, fica evidente a falta de discussão e de aprofundamento no ensino sobre quem e o que faz parte dessa "biodiversidade", dentre as objetividades e subjetividades dos sujeitos e suas relações socioambientais. Como afirma Morin (2005, p. 23),

\footnotetext{
A reforma necessária do pensamento é aquela que gera um pensamento do contexto e do complexo. O pensamento contextual busca sempre a relação de inseparabilidade e as interretroações entre qualquer fenômeno e seu contexto, e deste com o contexto planetário. $\mathrm{O}$ complexo requer um pensamento que capte relações, inter-relações, implicações mútuas, fenômenos multidimensionais, realidades que são simultaneamente solidárias e conflitivas (como a própria democracia, que é o sistema que se nutre de antagonismos e que, simultaneamente, os regula), que respeite a diversidade, ao mesmo tempo em que a unidade, um pensamento organizador que conceba a relação recíproca entre todas as partes.
}

Nesse sentido, observamos que o texto da BNCC não ignora os referenciais e as diretrizes curriculares, no entanto minimiza as questões socioambientais, dando enfoque ao não-lugar da formação ambiental na EB, temática imprescindível ao ensino e à aprendizagem na busca por um processo de emancipação e de justiça ambiental. À vista disso, a EA, ao olhar crítico que enfrenta percepções de práticas pedagógicas minimizadoras e que nada ou pouco discutem sobre as problemáticas socioambientais na EB, precisa estar contextualizada na formação de professores. Nessa perspectiva, como evidencia Oliveira (2017, p.130), 
A formação de educadores(as) precisa estimular a capacidade de criação e, assim, possibilitar ao(à) educador(a) constituir-se como ser social responsável, capaz de autoformar-se, refletir sobre a sua prática, cooperar e relacionar-se eticamente.

Logo, a importância do trabalho com as questões ambientais, bem como o envolvimento da dimensão dos conhecimentos, dos valores e da participação política na prática pedagógica e na formação docente são sui generis para a EA crítica (CAMPOS; CAVALARI, 2018).

\section{O NÃO LUGAR DA FORMAÇÃO AMBIENTAL NA BNC-FORMAÇÃO}

Marcelo (1998), ao discorrer sobre o processo de elaboração de programas para a formação de professores, reforça que uma fase indispensável para a construção desses programas é o "diagnóstico de necessidades dos professores". O autor enuncia que esse diagnóstico precisa considerar, ao menos, duas perspectivas diferentes: as carências, os desejos e as dificuldades enfrentadas pelos professores em sua prática pedagógica; e as necessidades estabelecidas pela disparidade entre o que de fato é a prática pedagógica realizada e o que esta deveria ser. A partir de dos documentos em questão analisados, constatamos necessidades e dificuldades acerca da inserção da temática socioambiental na formação docente, e por conseguinte no contexto escolar. Essas dificuldades surgem em virtude da formação oferecida a esses profissionais, que precariza a inserção da temática ambiental nos currículos.

A influência da formação de um professor sobre a sua prática pedagógica é imensa, pois esta pode impossibilitar ou ampliar a prática da EA na escola. Em razão disso, é imprescindível que os currículos de cursos de formação docente sejam elaborados de modo a atenderem à necessidade da inserção da temática socioambiental na formação do educador (FERREIRA, 2010).

A partir da análise do texto da BNC-Formação, verificamos que a temática socioambiental é apresentada de maneira superficial, quando o é. Ao longo das 20 páginas do documento em questão, a palavra "ambiental" é citada apenas uma vez e de forma genérica, restrita ao termo "consciência socioambiental". Os demais termos relacionados à temática ambiental são as palavras "sustentáveis", "planeta" e "consumo responsável".

No anexo que apresenta as competências gerais docentes, as expressões "consciência socioambiental", "consumo responsável" e "planeta" estão presentes no item 7, que discorre o seguinte:

Desenvolver argumentos com base em fatos, dados e informações científicas para formular, negociar e defender ideias, pontos de vista e decisões comuns, que respeitem e promovam os direitos humanos, a consciência socioambiental, o consumo responsável em âmbito local, regional e global, com posicionamento ético em relação ao cuidado de si mesmo, dos outros e do planeta (BRASIL, 2019, p. 13).

O trecho citado é o mesmo que consta na competência número 7 da BNCC, com algumas alterações pontuais na escrita. Esse discurso aborda, de forma indireta, uma responsabilidade individual e coletiva, porém não elucida toda a sua complexidade. Assim, a consciência socioambiental é citada, contudo o seu significado não é discorrido, bem como o consumo responsável. Vale destacarmos que o consumo pode ser considerado como um tema indispensável às reflexões que tangem aos problemas socioambientais, visto que o consumo desenfreado é um dos hábitos mais presentes na sociedade e atua diretamente na produção de resíduos e também de produtos para atender à demanda. Além disso, a problemática do consumismo se vincula diretamente a outros problemas socioambientais, como a pobreza e as desigualdades sociais. Então, a partir da superficialidade da discussão desse tema no texto da BNC-Formação,

Fica claro que as políticas educacionais estão coniventes com as políticas neoliberais que enfatizam seu papel social, reproduzindo a discussão ambiental sem aprofundamento das questões econômicas, políticas, culturais, sociais ou mesmo do conhecimento específico que justifica a complexa dinâmica a qual insere esse tema (SANTINELO; ROYER; ZANATTA, 2016, p. 113). 
A promoção da consciência socioambiental é apresentada no documento referido de forma breve e, dessa forma, mostra-se como uma limitação da discussão socioambiental crítica. Logo, a supressão dessa temática no currículo dos cursos de formação de professores dificultará a prática da reflexão acerca das questões socioambientais que são amplamente complexas. Diante disso, defendemos que é fundamental que os professores recebam uma formação munida de um embasamento socioambiental que parta de uma perspectiva crítica e emancipatória. A discussão dos problemas socioambientais precisa ser inserida de forma mais abrangente nas políticas de formação de professores e nos currículos, pois, de acordo com Jacobi (2003, p. 200),

A problemática socioambiental, ao questionar ideologias teóricas e práticas, propõe a participação democrática da sociedade na gestão dos seus recursos atuais e potenciais, assim como no processo de tomada de decisões para a escolha de novos estilos de vida e a construção de futuros possíveis, sob a ótica da sustentabilidade ecológica e a eqüidade social.

Refletindo nessa mesma direção, Araújo (2004, p.77) argumenta que “(...) a formação, quando reduzida à preparação técnica, não prepara o professor para solucionar problemas oriundos da incerteza, da singularidade e dos conflitos de valores que escapam aos cânones da racionalidade técnica". Assim, Schön (1995) chama a atenção para o fato de que os professores, sob a perspectiva posta nos cursos de formação, não dão conta de responder as questões que se apresentam em muitas situações concretas no cotidiano escolar e aos objetivos propostos por uma educação que vise às transformações sociais. O mesmo raciocínio é seguido por Gadotti (2001, p. 88), quando afirma que "nossos cursos de formação do educador, em geral, preocupam-se muito com métodos, técnicas, meios de ensinar, orientar, supervisionar ou coordenar uma sala de aula, mas evitam a questão política da educação.

Desse modo, vemos que a promoção da temática socioambiental na formação de professores é indispensável, pois essa é a única forma de fomentar a discussão dos problemas sociais e ambientais dentro das escolas e também nas comunidades em que elas estão inseridas. O enfrentamento desses problemas se inicia a partir de uma reflexão crítica no que tange às questões ambientais.

$\mathrm{Na}$ décima competência geral docente traçada na BNC-Formação, o termo "sustentabilidade" surge desvinculado de qualquer outro termo que remeta à temática ambiental:

Agir e incentivar, pessoal e coletivamente, com autonomia, responsabilidade, flexibilidade, resiliência, a abertura a diferentes opiniões e concepções pedagógicas, tomando decisões com base em princípios éticos, democráticos, inclusivos, sustentáveis e solidários, para que o ambiente de aprendizagem possa refletir esses valores (BRASIL, 2019, p. 13).

Como visto, o termo "sustentáveis" é apresentado de forma independente e fragmentada, não havendo nenhum tipo de descrição sobre o que o termo significa ou de que forma ele deve ser trabalhado. A ausência de uma apresentação mais complexa dessa temática não é satisfatória, pois, a partir do desenvolvimento da postura sustentável, é possível avivar o sentimento de cidadania e também da responsabilidade socioambiental.

Essas reflexões críticas, na formação de professores, caracterizam-se como um importante elemento capaz de romper com práticas tradicionais, apontadas por Freire (2005) como educação bancária $^{8}$, e que estão a serviço da opressão atrelada a um modelo de sociedade pautado na racionalidade instrumental.

O movimento de pensar criticamente a ação deve propiciar a fusão entre prática e teoria (práxis), alicerce da construção de uma pedagogia apropriada para a EA (ARAÚJO, 2004). Nesse viés, a formação dos educadores para o trabalho com a EA deve possibilitar a articulação entre o saber pedagógico e o saber ambiental. Para tanto, faz-se necessária a superação do modelo tradicional de formação, construindo-se práticas pedagógicas para além de propostas centradas na racionalidade constituinte/constituída que objetivam o controle do saber e o exercício do poder.

\footnotetext{
${ }^{8} \mathrm{Na}$ concepção bancária, segundo a qual a educação é o ato de depositar, de transferir, de transmitir valores e conhecimentos, não se verifica nem se pode verificar a superação da hegemonia que está posta. Pelo contrário, refletindo a sociedade opressora e sendo dimensão da cultura do silêncio, a educação bancária mantém e estimula a contradição (FREIRE, 2005).

Educação em Revista|Belo Horizonte|v.37|e26552|2021
} 
Destarte, é perceptível o não-lugar da formação ambiental na BNC atual, em que as temáticas socioambientais são tratadas de forma superficial e fragmentada, não recebendo a complexidade que lhes concerne. Ademais, esse não-lugar da formação ambiental na BNC-Formação contribui para uma constituição identitária docente perpassada pela falta de reconhecimento do lugar dos professores frente à problemática socioambiental. Os docentes, por não terem acesso a um processo formativo que enfoque a dimensão ambiental da educação, reconhecem e tomam como lugar na sociedade e na ação pedagógica o não-lugar incutido pelos currículos de licenciatura balizados pelo documento orientador em pauta, tornando-se sujeitos reprodutores dos interesses da ordem dominante do status quo.

\section{CONSIDERAÇÕES FINAIS: O NÃO-LUGAR DA FORMAÇÃO AMBIENTAL NA EDUCAÇÃO BÁSICA}

Em síntese, alicerçadas nas discussões realizadas neste estudo, podemos concluir que a temática socioambiental está disposta na BNCC e na BNC-formação, mas não de forma satisfatória alinhada na perspectiva crítica da EA, visto que não trazem elementos discursisvos em seus textos que permitam compreender a educação e a problemática socioambiental em uma perspectiva crítica, fomentando, assim, explícita e implicitamente, a reprodução de discursos e ações de caráter conservacionista e pragmático tanto na Educação Básica quanto na formação docente, conforme evidenciado no aporte teórico e na análise realizada. Essa é uma realidade preocupante, pois uma formação inicial de professores que aborde a EA crítica, emancipatória e seus temas afins contribui para a estruturação de uma sociedade cada vez mais reflexiva e responsável socioambientalmente.

Em consonância com Andrade e Piccinini (2017), não acreditamos que os sujeitos responsáveis pela BNCC e pela BNC-Formação esqueceram-se de apresentar a EA ou os temas socioambientais de forma abrangente, mas sim que essa superficialidade se dá a partir de uma escolha política baseada no distanciamento do crítico da educação das questões socioambientais presentes na realidade escolar, questões essas que deveriam ser discutidas e refletidas também durante a formação dos professores.

É preciso continuar as reflexões sobre como as temáticas socioambientais vêm sendo trabalhadas nas políticas educacionais de formação de professores, por essa reflexão ser indispensável para que possamos contribuir com o enfrentamento dos problemas socioambientais, partindo do individual ao coletivo, da escola à comunidade. Uma formação ambiental é imprescindível para que os professores, atuando na EB, possam contribuir com a formação de uma sociedade consciente e responsável socioambientalmente.

Por fim, na atual configuração curricular brasileira observada nos documentos aqui analisados, centrada na disciplinarização do conhecimento e distante das questões socioambientais e das práticas cotidianas, o tratamento fragmentado e reducionista da EA não contribui para uma verdadeira democratização do ensino escolar e da formação docente, além de não incentivar e de não colaborar para a transformação da sociedade brasileira, caracterizada por tantas desigualdades.

Todavia, é mister destacar que os resultados aqui elencados remetem à uma análise qualitativa balizada pelos conteúdos discursivos presentes na BNCC e na BNC-Formação e que, por isso, novos estudos são necessários para aprofundamento da discussão e, por conseguinte, novos olhares acerca das percepções ora identificadas e das limitações que o recorte feito sobre o objeto deixam à mostra. No entanto, este estudo abre horizontes para que possamos começar a questionar o cenário formativo que se delineia no país através dos documentos supracitados e, quiçá, levantar possibilidades de luta e enfrentamento ao retrocesso legitimado curricularmente na Educação Básica e no Ensino Superior.

Diante disso, esperamos que esta pesquisa possa desencadear novas perguntas e novos olhares que aprofundem as questões, o pensar e o agir da EA, ajudando a esclarecer caminhos, apontando para a concretização da EA crítica nos espaço diversos de formação e buscando alternativas que superem o modelo da racionalidade hegemônica dominante. Esperamos, ainda, que possa despertar nos sujeitos a percepção da tomada de lugar na sociedade dentro do processo de enfrentamento à problemática socioambiental e de desnaturalização do não-lugar ao qual a formação ambiental está sendo direcionada devido à abordagem realizada pela BNC-Formação, pois a tomada de lugar implica a tomada de consciência que mobiliza a transformação societária. 


\section{REFERÊNCIAS}

ANDRADE, Maria Carolina Pires de; PICCININI, Cláudia Lino. Educação Ambiental na Base Nacional Comum Curricular: retrocessos e contradições e o apagamento do debate socioambiental. In: ENCONTRO PESQUISA EM EDUCAÇÃO AMBIENTAL, 9, 2017. Anais... Juiz de Fora: UFJF, 2017. Disponível em: http://epea.tmp.br/epea2017 anais/pdfs/plenary/0091.pdf. Acesso em: 25 jul. 2020.

ARAÚJO, Maria Inêz Oliveira. A universidade e a formação de professores para a educação ambiental. Revista Brasileira de Educação Ambiental, Brasília, n. 0, p. 71-78, nov. 2004.

AUGÉ, Marc. Não-lugares: introdução a uma antropologia da supermodernidade. Tradução de Maria Lúcia Pereira. 7. ed. São Paulo: Papirus, 1994.

BAUMAN, Zygmunt. Globalização: As Consequências Humanas. Tradução de Marcus Penchel. Rio de Janeiro: Editora Jorge Zahar, 1999.

BAUMAN, Zygmunt. Comunidade: a busca por segurança no mundo atual. Tradução de Marcus Penchel. Rio de Janeiro: Editora Jorge Zahar, 2003.

BRASIL. Lei $\mathbf{n}^{\mathbf{0}}$ 9.795, de 27 de abril de 1999. Dispõe sobre a educação ambiental, institui a Política Nacional de Educação Ambiental e dá outras providências. Brasília, DF, 1999. Disponível em: http://www.planalto.gov.br/ccivil_03/leis/19795.htm. Acesso em: 02 jan. 2020.

BRASIL. Conselho Nacional de Educação. Resolução $\mathbf{n}^{\circ}$ 2, de 15 de junho de 2012. Estabelece as Diretrizes Curriculares Nacionais para a Educação Ambiental. Brasília, DF, 2012. Disponível em: http://portal.mec.gov.br/dmdocuments/rcp002_12.pdf. Acesso em: 02 jan. 2020.

BRASIL. Conselho Nacional de Educação. Resolução $\mathbf{n}^{\circ}$ 2, de $1^{\circ}$ de julho de 2015. Define as Diretrizes Curriculares Nacionais para a formação inicial em nível superior (cursos de licenciatura, cursos de formação pedagógica para graduados e cursos de segunda licenciatura) e para a formação continuada. Disponível em: http://portal.mec.gov.br/docman/agosto-2017-pdf/70431-res-cne-cp-002-03072015pdf/file. Acesso em: 23 jul. 2020.

BRASIL. Conselho Nacional de Educação. Resolução $\mathbf{n}^{\circ}$ 2, de 22 de dezembro de 2017. Institui e orienta a implantação da Base Nacional Comum Curricular, a ser respeitada obrigatoriamente ao longo das etapas e respectivas modalidades no âmbito da Educação básica. Disponível em: http://basenacionalcomum.mec.gov.br/images/historico/RESOLUCAOCNE_CP222DEDEZEMBR ODE2017.pdf. Acesso em: 16 jul. 2020.

BRASIL. Conselho Nacional de Educação. Resolução $\mathbf{n}^{\mathbf{0}}$ 2, de 02 de dezembro de 2019. Define as Diretrizes Curriculares Nacionais para a formação inicial de professores para a Educação Básica e institui a Base Nacional Comum para a formação inicial de professores da Educação Básica (BNC-Formação). Brasília, DF, 2019. Disponível em: http://portal.mec.gov.br/docman/dezembro-2019-pdf/135951rcp002-19/file. Acesso em: 02 jan. 2020.

BRASIL. Ministério da Educação. Base Nacional Comum Curricular. Brasília: MEC, 2018. Disponível em: http://basenacionalcomum.mec.gov.br/. Acesso em: 02 jan. 2020.

CAMPOS, Daniela Bertolucci de; CAVALARI, Rosa Maria Feiteiro. O professor de Biologia enquanto "sujeito ecológico": conhecimentos, valores e participação política na prática docente. Revista Eletrônica de Educação, v. 12, n. 1, p. 184-198, jan./abr. 2018. Disponível em: http://www.reveduc.ufscar.br/index.php/reveduc/article/view/1899/678. Acesso em: 23 jul. 2020.

FERREIRA, Carla Fernanda Bernardino. Formação de professores: concepções e práticas pedagógicas de educação ambiental. Dissertação (Mestrado em Educação) - Instituto Federal de Educação, Ciência e Tecnologia do Rio de Janeiro, Rio de Janeiro, 2010. 
FREIRE, Paulo. Conscientização: teoria e prática da libertação: uma introdução ao pensamento de Paulo Freire. São Paulo: Cortez \& Moraes, 1979. Disponível em: http://www.dhnet.org.br/direitos/militantes/paulofreire/paulo_freire_conscientizacao.pdf. Acesso em: 16 jul. 2020.

FREIRE, Paulo. Pedagogia da autonomia: saberes necessários à prática educativa. 37. ed. São Paulo: Paz e Terra, 1996.

FREIRE, Paulo. Pedagogia do oprimido. 49. reimp. Rio de Janeiro: Paz e Terra, 2005.

GADOTTI, Moacir. Pedagogia da práxis. 3. ed. São Paulo: Cortez, 2001.

GUIMARÃES, Mauro. A formação de educadores ambientais. São Paulo: Papirus, 2004.

GUIMARÃES, Mauro. Por uma Educação Ambiental crítica na sociedade atual. Revista Margens Interdisciplinar, v. 7, n. 9, p. 11-22, maio 2016. ISSN 1982-5374. Disponível em: https://periodicos.ufpa.br/index.php/revistamargens/article/view/2767/2898. Acesso em: 16 jul. 2020.

HALL, Stuart. A identidade cultural na pós-modernidade. Rio de Janeiro: DP\&A, 2005.

JACOBI, Pedro. Educação ambiental, cidadania e sustentabilidade. Cadernos de pesquisa, n. 118, p. 189-206, 2003.

LAYRARGUES, Philippe Pomier. Éducation à l'environnement et anti-écologisme au Brésil: un modèle d'enseignement au service de la reproduction sociale. Droit et cultures, n.78, 2019. Disponível em: http://journals.openedition.org/droitcultures/5544. Acesso em: 02 mai. 2021.

LAYRARGUES, Philippe Pomier. Para onde vai a educação ambiental? O cenário político-ideológico da educação ambiental brasileira e os desafios de uma agenda política crítica contra-hegemônica. Revista Contemporânea de Educação, vol. 7, n. 14, agosto/dezembro de 2012. p. 388-411. Disponível em: https://revistas.ufrj.br/index.php/rce/article/download/1677/1526. Acesso em: 02 mai. 2021.

LEFF, Enrique. Saber ambiental: sustentabilidade, racionalidade, complexidade, poder. Tradução de Lúcia Mathilde Endlich Orth. 5. ed. Petrópolis: Vozes, 2007.

LOUREIRO, Carlos Frederico Bernardo. Trajetória e fundamentos da educação ambiental. 2.ed. São Paulo: Cortez, 2012.

MARCELO, Carlos. Pesquisa sobre a formação de professores: o conhecimento sobre aprender a ensinar. Revista Brasileira de Educação, v. 9, p. 51-75, set-dez, 1998.

MORAES, Roque; GALIAZZI, Maria do Carmo. Análise textual discursiva. 2. ed. Ijuí: Editora Unijuí, 2013.

MORIN, Edgar. Ciência com consciência. Rio de Janeiro: Bertrand, 2000.

MORIN, Edgar. Introdução ao pensamento complexo. Tradução de Eliane Lisboa. Porto Alegre: Sulina, 2005.

MORIN, Edgar. Introdução ao pensamento complexo. Tradução de Eliane Lisboa. 5.ed. Porto Alegre: Sulina, 2015.

NÓVOA, Antônio. Os professores e a sua formação. Lisboa: Publicações Dom Quixote, 1995.

OLIVEIRA, Aline L. A perspectiva participativa para a inserção da educação ambiental crítica em escolas da Baixada Fluminense. 143 f. Dissertação (Mestrado em Educação), Instituto de Educação/Instituto Multidisciplinar, Universidade Federal Rural do Rio de Janeiro, Seropédica/Nova Iguaçu, 2012.

OLIVEIRA, Alilne L. Das tensões políticas à prática pedagógica socioambiental: contextos da política estadual de educação ambiental (SE). 2017. 242 f. Tese (doutorado em Educação) - Universidade Federal de Sergipe, São Cristóvão, 2017. 
PIMENTA, Selma Garrido; GHEDIN, Evandro. Professor reflexivo no Brasil: gênese e crítica de um conceito. São Paulo: Cortez, 2002.

SANTINELO, Paulo Cesar Canato; ROYER, Maria Regina; ZANATTA, Shalimar Calegari. A Educação ambiental no contexto preliminar da base nacional comum curricular. Pedagogia em Foco, v. 11, n. 6, p. 104-115, 2016.

SCHÖN, Donald A. Formar professores como profissionais reflexivos. In: NÓVOA, Antônio (Org.). Os professores e sua formação. Lisboa: Dom Quixote, 1995. p. 77-91.

TARDIF, Maurice. Princípios para guiar a aplicação dos programas de formação inicial para o ensino. In: PERES, Eliane et al. (Orgs.). Trajetórias e processos de ensinar e aprender: didática e formação de professores. Porto Alegre: EDI- PUCRS, 2008. p. 17-46.

TREIN, Eunice Schilling. A educação ambiental crítica: crítica de que? Revista Contemporânea de Educação, vol. 7, n. 14, agosto/dezembro de 2012. p. 295-308. Disponível em: https://revistas.ufrj.br/index.php/rce/article/view/1673/1522. Acesso em: 02 mai. 2021.

Submetido: $03 / 12 / 2020$

Aprovado: 07/07/2021 